\title{
A Multidisciplinary Approach for the Treatment of Intermediated to Advanced Hepatocellular Carcinoma - Is it Still Optional?
}

\section{Choong Nam Shim ${ }^{1}$ and Jun Yong Park ${ }^{1,2,3,4 *}$}

1 Department of Internal Medicine, Seoul, Korea

${ }^{2}$ Institute of Gastroenterology, Seoul, Korea

${ }^{3}$ Liver Cancer Special Clinic, Yonsei University College of Medicine, Seoul, Korea

${ }^{4}$ Liver Cirrhosis Clinical Research Center, Seoul, Korea

Hepatocellular Carcinoma (HCC) is endemic in Asia. It is expected that about $80 \%$ of new HCC cases worldwide will develop in Asia $[1,2]$. Screening programs improve the detection of early HCC and have a positive impact on survival, but the majority of HCC patients in Asia still present with advanced stage disease. Although surgical resection is generally accepted as the most effective treatment for HCC, most patients with advanced HCC are not suitable candidates for surgical treatment at the time of diagnosis because of extensive tumor involvement of the liver, vascular invasion, intrahepatic or extrahepatic spread as well as poor liver function. Therefore, unfortunately most patients are eligible for only palliative treatments.

The treatment outcomes of HCC are affected by various factors, including liver function, performance status of the patient and tumor stage. For optimal management, the treatment choice is guided by staging systems and treatment guidelines. To date, several staging systems and treatment guidelines have been proposed for each region. According to the Barcelona Clinic Liver Cancer guideline based on evidence from randomized clinical trials, only Transarterial Chemoembolization (TACE) is recommended for intermediate stage and sorafenib for advanced stage [3-5]. However, treatment guidelines from Asian countries have adopted several other therapeutic modalities such as a surgical approach, hepatic arterial infusion chemotherapy, external radiation, and their combinations based on clinical experiences for intermediate and advanced stage HCC.

In the intermediate stage, although TACE is the main therapeutic modality of it, overall therapeutic outcomes depend on the tumor size. When HCCs are larger than $3 \mathrm{~cm}$, complete necrosis is seldom observed through TACE [6,7]. To improve loco-regional therapies for patients with unresectable HCC, new liver-directed therapies have emerged. Preliminary results of the use of Drug-Eluting Beads (DEBs) suggest that this approach is associated with a favorable toxicity profile and encouraging antitumor activity [8-10]. In a recent study comparing conventional TACE with DEB-TACE, the DEB-TACE group resulted in a compatible local response, fewer recurrences, lower side effect and a longer time to progression compared to the conventional TACE group [11]. Radioembolization with Yttrium-90-embedded microspheres is a new method suggesting an effective treatment approach for patients with unresectable HCC [12]. TACE followed by Radio Theraphy (RT) has been reported to improve tumor response and overall survival over TACE alone [13]. Localized concurrent chemoradiation therapy followed by repetitive hepatic arterial infusional chemotherapy in locally advanced HCC has shown promising results $[14,15]$. Therefore, combinations of local regional treatments along with sorafenib which is the standard care of advanced stage HCC, might be also considered in the advanced stage, according to the tumor status, e.g. major vessel invasion or extra hepatic spread.

There are still many therapeutic options aside from sorafenib for the locally advanced stage based on Asian experts' opinions. Despite the concentrated efforts of all kinds of medical specialties to improve survival, the results have still achieved limited success. Therefore, a multidisciplinary approach may be mandatory to improve patients' survival by inter-department cooperation. And multidisciplinary approach for the management of HCC may overcome current barrier and improve therapeutic efficacy leading to improve survival in the near future.

\section{References}

1. Curado MP, Edwards B, Shin HR, Storm H, Ferlay J (2010) Cancer Incidence in Five Continents. Lyon, IARC.

2. Kudo M, Han KH, Kokudo N, Cheng AL, Choi BI, et al. (2010) Liver Cancer Working Group Report. Jpn J Clin Oncol 40: i19-i27.

3. Bruix J, Llovet JM (2002) Prognostic prediction and treatment strategy in hepatocellular carcinoma. Hepatology 35: 519-524.

4. Forner A, Reig ME, de Lope CR, Bruix J (2010) Current strategy for staging and treatment: the BCLC update and future prospects. Semin Liver Dis 30: 61-74.

5. Marrero JA, Kudo M, Bronowicki JP (2010) The challenge of prognosis and staging for hepatocellular carcinoma. Oncologist 15: 23-33.

6. Han KH, Lee JT, Seong J (2002) Treatment of nonresectable hepatocellular carcinoma. J Gastroenterol Hepatol 17: S424-S427.

7. Shim SJ, Seong J, Han KH (2005) Local radiotherapy as a complement to incomplete transcatheter arterial chemoembolization in locally advanced hepatocellular carcinoma. Liver Int 25: 1189-1196.

8. Malagari K, Chatzimichael K, Alexopoulou E (2008) Transarteria chemoembolization of unresectable hepatocellular carcinoma with drug eluting beads: results of an open-label study of 62 patients. Cardiovasc Intervent Radiol 31: 269-280.

9. Poon RT, Tso WK, Pang RW, Ng KK, Woo R, et al. (2007) A phase I/ II tria of chemoembolization for hepatocellular carcinoma using a novel intra-arterial drug-eluting bead. Clin Gastroenterol Hepatol 5: 1100-1108.

10. Varela M, Real MI, Burrel M, Forner A, Sala M, et al. (2007) Chemoembolization of hepatocellular carcinoma with drug eluting beads: efficacy and doxorubicin pharmacokinetics. J Hepatol 46: 474-481.

11. Lammer J, Malagari K, Vogl T, Pilleul F, Denys A, et al. (2010) Prospective randomized study of doxorubicin-eluting- bead embolization in the treatment of hepatocellular carcinoma: results of the PRECISION V study. Cardiovasc Intervent Radiol 33: 41-52.

12. Salem R, Lewandowski RJ, Mulcahy MF, Riaz A, Ryu RK, et al. (2010)

*Corresponding author: Jun Yong Park, MD, PhD, Department of Interna Medicine, Yonsei University College of Medicine, Yonsei-ro 50, Seodaemungu, Seoul, South Korea, Tel: +82-2-2228-1994; Fax: +82-2-393-6884; E-mail: drpjy@yuhs.ac

Received August 17, 2013; Accepted August 20, 2013; Published August 29 2013

Citation: Shim CN, Park JY (2013) A Multidisciplinary Approach for the Treatmen of Intermediated to Advanced Hepatocellular Carcinoma - Is it Still Optional? J Liver 2: e105. doi:10.4172/2167-0889.1000e105

Copyright: ( 2013 Shim CN, et al. This is an open-access article distributed unde the terms of the Creative Commons Attribution License, which permits unrestricted use, distribution, and reproduction in any medium, provided the original author and source are credited. 
Citation: Shim CN, Park JY (2013) A Multidisciplinary Approach for the Treatment of Intermediated to Advanced Hepatocellular Carcinoma - Is it Still Optional? J Liver 2: e105. doi:10.4172/2167-0889.1000e105

Page 2 of 2

Radioembolization for hepatocellular carcinoma using yttrium-90 microspheres: a comprehensive report of long-term outcomes. Gastroenterology 138: 52-64.

13. Seong J, Park HC, Han KH, Lee DY, Lee JT, et al. (2000) Local radiotherapy for unresectable hepatocellular carcinoma patients who failed with transcatheter arterial chemoembolization. Int J Radiat Oncol 47: 1331-1335.

14. Park JY, Ahn SH, Yoon YJ, Kim JK, Lee HW, et al. (2007): Repetitive short- course hepatic arterial infusion chemotherapy with high-dose 5-fluorouracil and cisplatin in patients with advanced hepatocellular carcinoma. Cancer 110:129137

15. Han KH, Seong J, Kim JK, Ahn SH, Lee do Y, et al. (2008) Pilotclinical trial of localized concurrent chemoradiation therapy for locally advanced hepatocellular carcinoma with portal vein thrombosis. Cancer 113: 995-1003. 